\title{
Urban infrastructure via Big Data
}

\author{
Wadim Strielkowski ${ }^{1 *}$, Marina Faminskaya $^{2}$, and Elena Potekhina $^{2}$ \\ ${ }^{1}$ University of California, 303 Giannini Hall, CA 94720, Berkeley, United States \\ ${ }^{2}$ Russian State Social University, 4/1 Wilhelm Pik str, Moscow, 129226, Russian Federation
}

\begin{abstract}
Our paper focuses on factors that help to successfully and efficiently manage urban infrastructure in large cities and centres using Big Data solutions. We explain the key points about urban Big Data approaches, including infrastructure that supports urban governance, public services and economic and industrial development, taking into account and supporting the central role of urban Big Data in urban intelligence with particular emphasis on the smart cities. Moreover, we want to add a third dimension to social urban data analysis by assessing the use of social, spatial, and temporal data for key issues to understand how it can influence human behaviour across time and space. Our results might have important implications for urban planners and policy-makers and contribute to the mitigating the regional inequalities as well as to improving urban infrastructure and making the cities of the future happier and healthier places for all their citizens.
\end{abstract}

Keywords: urban infrastructure, Big Data, area planning, sustainable development.

\section{Introduction}

Nowadays, when information and communication technologies (ICT) are becoming ubiquitous and penetrate every aspect of our daily lives, data analysis and visualisation are starting to make the key to the creation of the sustainable mobility and a liveable environment for citizens $[1,2]$. Data is also an important source of information for fleet operators who wish to offer new mobility services. It allows them to evaluate the best conditions for their business models to work. The provision of data analysis and visualization for transport models is one of the core competencies of the management of smart cities [3, 4].

Today's smart cities are designed to improve based on the needs of their populations, and data collection is key to economic growth and prosperity. This data can be analysed along with additional information on commuter habits, population density, and more by future urban planners looking to improve infrastructure [5]. As our cities grow and develop, we need all the data and analysis we can get to keep people safe, healthy and happy wherever they live. In the meantime, as our cities improve in terms of infrastructure and secure commuting, we can create new jobs and opportunities for people, especially skilled workers. Research into urban infrastructure with big data remains crucial to creating alternative pathways to a sustainable future $[6,7]$.

\footnotetext{
*Corresponding author: strielkowski@berkeley.edu
} 
With regard to the above, the Big Data become very important and can be used effectively for tackling all these issues. Although the limitations of Big Data are widely acknowledged in academic literature, we argue that big data offers important ways to unpack urban infrastructure $[8,9]$. While Big Data is surely not a panacea for urban ills, more research is needed to assess the opportunities and challenges ahead. This must reflect the usefulness of Big Data for urban development approaches relative to the value of urban infrastructure. This has altered our understanding of everyday urban movements and patterns through a combination of Big Data analysis and state-of-the-art computer simulations [10]. In addition, this has developed new methods of generating data that can help us tackle key issues such as crime and health. Many case studies support urban planning and policy development in a data-rich society. Big Data and advanced computer simulations can be used to understand how people move through cities [11]. This new knowledge can consequently be used to try to understand crime rates and assess the impact of air pollution on people's health.

In the age of transformative mobility, this can help to better design strategies and investment strategies for managing existing urban infrastructure and predicting future urban infrastructure planning. Data-driven research in urban data analysis is an interdisciplinary field in which machine learning and deep learning methods, computer science optimization and simulation methods, and surgical research are applied to conventional urban fields with spatiotemporal data [12]. A major focus of traffic planners, urban planners and geographers is to understand how urban systems function and develop through models of individual daily urban activities. The dilemma of planning and coordination need and their impossibility in detail has been solved by recognizing that cities are the first self-organizing social networks embedded in spaces that enable urban infrastructure and services [13]. In cities therefore, the primary role of Big Data is to facilitate information flow mechanisms for learning and coordination between heterogeneous individuals.

Urban infrastructure systems reflect previous studies of urban processes characterized by interconnected infrastructure landscapes [14]. They not only facilitate the flow of people, energy, water, materials and money from cities to and from them, but also contribute to the urban landscape. Infrastructure remains crucial in the debate about whether it brings greater health, economic, and environmental benefits to society than traditional calculations of cash returns. Researchers have found a strong link between poor infrastructure and reduced quality of life. Sophisticated urban planning and investment in stable infrastructure are indispensable to alleviate poverty and create jobs. The inclusion of Big Data applications to support smart cities is not only a challenge; successful implementation will lead cities towards a so-called smart city. This provides one of the ways how to define smart urban development: one needs to identify her or his mission, vision, strategic and operational goals. Then, she or he needs to optimize smart city services and operations by using the collected data from smart applications to improve services and identify necessary infrastructure and environmental improvements. This is followed by integrating infrastructure and services with Big Data and smart city applications to develop better and more efficient citizen experiences $[15,16]$.

In short, the use of ICT and information technologies, including smart meters and Big Data, offers numerous opportunities to develop applications for smart cities that meet the needs of the different entities that live and use smart cities [17]. It is crucial to recognise the new opportunities for further development, monitor current developments and their effects and make new demands. As the evolving urban world becomes ever more technologically advanced and computer-based on Big Data, the prospects are becoming clear that smart and sustainable cities can be enabled and developed by harnessing core technologies such as Big Data analytics and related novel applications to meet the needs of diverse urban components to meet their needs in an unsustainable urbanized world [18]. This will require huge investments in the kind of resources, infrastructure, platforms and expertise needed to support construction and deployment of core technology from Big Data analysis in the various design 
and development phases of smart and sustainable cities [19]. This is considered indispensable to reap the environmental and socio-economic benefits of sustainability in such cities. Urban planners and policymakers in developing countries need to break with the historical theory of migration effects and correct themselves.

\section{Big data and decision-making}

Some cities (such as the New York City) use Community Boards of small government agencies which are composed of volunteers who help make decisions in their neighbourhoods and act as advisory bodies to city agencies. The use of Big Data analysis enables the prediction of socio-economic, environmental and demographic changes and the development of novel solutions to integrate and consolidate design strategies for sustainable cities in order to mitigate fragmentation in their design and environmental technologies [20,21].

At the applied research level, Big Data can be integrated to inform urban planning and governance using methods developed by teams in interactive planning support systems to visualize planning effects and provide tools for designers, policymakers, citizens, and other stakeholders. Big Data can also contribute to scenarios for responsive cities by exploring design scenarios in which it can create high-density cities and archipelago city scenarios with mixed use [22]. Moreover, Big Data methods offer new opportunities to design decision models for urban planning and management. The increasing flood of urban data represents a fundamental shift in the type of data generated by urban systems and the environment, what is happening and what will happen, and how to develop more effective measures to improve the planning and design of data-driven, smart, and sustainable cities of the future.

The use of Big Data analysis allows new theories to be developed about how these cities will function, in a way that focuses less on short-term sustainability issues, more on human mobility and physical movement, and more on long-term urban functioning in terms of sustainable development [23]. The combination of social media, census sensors and traditional data opens up a new perspective to address modern urban challenges with a holistic and inclusive approach. Adopting a holistic understanding of urban infrastructure makes it possible to think about cities in a time of uncertainty. Case studies can support urban planning and policy development in a data-rich society. There is huge potential to use Big Data analysis to address many pressing problems and serious problems in smart and sustainable cities through innovative solutions, sophisticated approaches, new high-level intelligence-driven decision-making practices, and enabling analytical outcomes from urban data overload [24, 25]. Advanced forms of ICT on which data analysis is based are required for interdisciplinary and transdisciplinary knowledge in sustainable and intelligent urban development, which is a complex field of study. Smart, sustainable cities provide a wide range of opportunities in terms of sustainability dimensions and their integration by dismantling big data as a synergistic, substantial, developable, expandable, dynamic, scalable and reliable Big Data ecosystem [26].

While the marketing rhetoric of "smart cities" is full of unfulfilled promises and the continued use and misuse of the term "Big Data" have created confusion and distrust of potential applications, the reality remains that the disruptive shift towards ubiquitous data collection, including mobile devices, GPS, social media, synoptic videos and the ability to store, manage and analyse vast data sets, requires urban planners to develop new skills to respond to these innovations. Faced with tightening budgets and increased demand for urban services, many cities such as New York, Chicago, or Pittsburgh in the United States made new efforts to overcome the mismatch of innovation incentives and processes between existing organizational and institutional structures to cultivate internal citizen-oriented capacities for data research and discovery with encouraging results. In this regard, it has been proposed that sustainable cities must embrace and capitalise on the advances made by ICT to 
improve, drive forward and sustain their contribution to sustainability [27, 28]. It was also recognized that the increasing networking of infrastructure networks creates opportunities to redesign decision-making processes, to enable new experimental sites, and to make urban infrastructure more stimulating and inclusive [29]. Such discussions are particularly relevant today, as the combination of human and non-human elements of urban life in the ongoing emergence and redesign of contemporary cities is incorporated [30]. With the increasing amount of data available to the public, the ability to analyse and respond to such data is a special capability that is becoming increasingly important for designers and planners. One should also remember that the term Big Data, which applies to a wide range of topics, generally refers to data from more than 50,000 observations, which is larger than a Microsoft Excel spreadsheet can handle. Since 2012, when the United States Big Data Research and Development Initiative was launched by the Obama administration, much of Big Data is open source and accessible to anyone interested in and who has access to this kind of information [31].

\section{Urban infrastructure systems}

With cities accounting for more than $80 \%$ of global GDP, urbanization can contribute to sustainable growth by driving productivity gains and generating innovation and new ideas. Urbanization has the potential to foster economic growth but the extent to which this potential is realized will likely depend on conducive institutional frameworks and adequate investment in public infrastructure [32]. The evidence gathered in this paper suggests that the development effects of urbanization and the extent of economic agglomeration vary widely.

The speed and scale of urbanization bring challenges, including meeting accelerating demand for affordable housing, well-connected transportation systems, and other infrastructure for basic services and jobs, as well as the 1 billion poor urban dwellers living in informal settlements without opportunities. Conflicts are on the increase, resulting in $60 \%$ of displaced persons living in urban areas [33]. It is crucial to invest in urban infrastructure to limit the destructive effects of massive population movements. They provide a conducive environment for physical and social infrastructure, human capital, financial systems, technical assistance and responsive governance. Capacity building and development through urban planning, design and investment decisions enable professionals to create, develop and manage green infrastructure. Urban policy and planning can strengthen different levels of governance and potential urban green infrastructure in order to strengthen urban resilience in different municipal and organisational contexts, urban climate, socio-economic and cultural environment.

Smart cities use data and technology to improve efficiency, sustainability, economic development and the quality of life of people living and working in cities. According to the definition of an intelligent city given by Caragliu and Del Bo [34], a city is intelligent if the investment of human and social capital in urban infrastructure promotes sustainable growth, improves the quality of life and supports participatory governance. Improving safety, resilience, sustainability, congestion, public safety, urban services, and communities is another reason to be smart. A clear role for social scientists is to understand and articulate how social infrastructure is put into practice and why it is important. Geographers have presented an infrastructural approach to public space as a productive tool for understanding public life in cities. Thinking about social infrastructure provides a solid explanation of why places like libraries, parks, community centres, beach cafes play a role in a city's collective public life. The argument for investigating social infrastructure is based on the research that looks at the value of places such as gyms, cafes, skate parks, swimming pools and football fields and tries to articulate why these places matter. It is a situated approach, based on our research in Europe, North America and New Zealand and an approach that combines with 
other research on similar topics in other parts of the world [35]. In addition, integrating environmental infrastructure into urban ecological infrastructure (UEI) can help bridge urban scientists and practitioners in transdisciplinary partnerships to build more resilient and sustainable cities.

Urban ecosystems are undergoing massive changes driven by social, ecological and technological processes. The need to further develop the concept of urban ecosystems is to combine the comprehensive knowledge of cultural and social systems and hierarchies of value developed through the work of our social scientists, the knowledge of infrastructure needs of our engineering colleagues and creativity and vision of our designers with the practical understanding of practitioners who make the everyday decisions in cities. A more inclusive approach to the urban ecosystem, taking into account ideas from different perspectives, will be a better understanding of the pathways for transformative action in our cities.

An ecological framework is the one that meets government objectives and is oriented to different environments for an urban ecological network [36]. This framework is based on the assumption that existing landscape elements can be modified to establish ecological networks and develop urban infrastructure. As a result, the framework includes the evaluation of natural and cultural resources as well as the formation of open spaces and spatial structures. In the evaluation process of the framework, network evaluation and analysis methods are used to measure the linkages within the landscape. A map of the existing open spaces and the continuity of the landscape is created by examining the area on the basis of the current soil cover. Based on the evaluation of this map, the potential impacts of infrastructure development on landscape continuity can be estimated. Resilience is a conceptual framework that has emerged in ecology and has been applied to ecosystems. Within this conceptual framework, resilience is incorporated into the analysis of social systems and communities, and it is an ecosystem service that refers to the ability of communities to recover from disruption without outside assistance (see Cutter et al. [37]). Social resilience is the capacity of communities to evolve and recover from external shocks to their social infrastructure. Social sustainability ensures the maintenance of the diverse social relationships that exist in healthy communities. The creation of physical, cultural and social spaces that foster wellbeing and a sense of community requires a process of engagement with the people who inhabit them. The idea of urban ecosystems was challenged by the urban bias of nineteenth and twentieth-century ecologists, who saw urbanized landscapes as worthless, polluted, and cut off by infrastructure networks. Despite the importance of infrastructure, some cities do not keep maintaining and improving it. This new type of needed infrastructure represents a major change in the way projects are financed.

\section{Big Data for operation and interaction with citizens}

During the COVID-19 pandemic, Big Data was collected to minimize the impact of the disease. Big data encompasses data quantities that exceed the capacity of conventional software to process in acceptable time and value [38]. The analysis of Big Data presents the challenge of sampling, which only allows observational samples. In its current use, the term "Big Data" tends to refer to the use of predictive analytics, user behaviour analysis and certain other advanced methods of data analysis to extract values from large data, due to the particular size of the data set. Simply put, Big Data is a huge volume of data that is either structured or unstructured. The quantity of data sets prevents the effectiveness of traditional analysis methods. Instead of focusing on the precise relationships between individual data sets, big data uses various algorithms and techniques to derive general trends across the entire data set. Analytics picks up on trends and predicts what will happen in the future. Careful 
analysis of Big Data can help state and local governments understand the mistakes they have made in the past [39].

The public sector and government services know how to generate and use huge amounts of data. In fact, governments worldwide save tens of billions every year through the use of Big Data. The emergence of Big Data adds a new dimension to the conception and use of digital technologies for the provision of public services and the implementation of digital governance. In many ways, the current discourse on big data echoes and repeats established comments from the e-government research community. Big Data's value proposition is clear: to address complex technical and business problems, but the jury is still out on how much better it can solve complex social problems [40]. The problems that need to be addressed in the social sector are more complex than in economics or in science, which make the use of big data more difficult.

Most organizations collect data to meet operational requirements, and that data is buried in their management systems. Novel controls, process standards and greater transparency in the use of data can help build trust. Some governments are seeking to introduce more technology-based services, and some are more reassurance for the public about their management of data and analysis (D\&A). This requires improvements in the origin, exchange and integration of data in the public sector [41]. It is also important to provide integrated security and data protection mechanisms for big data applications, as the government sector collects enormous amounts of sensitive data. The public value of data use and reuse is visible in itself, but is supported by a broader ecosystem of data management that creates the conditions under which the data can be used. The first two phases of the government's data value cycle are shaped by citizens' experiences that influence how to maintain trust in government and public value, and the process phase should be followed to identify the potential for creating new public value through data-sharing and research activities, as well as through policy implications and service opportunities. The third phase of the cycle looks at how data is stored, backed up, processed, shared, curated and published. At this stage of the process, the potential impact of the use of data is no longer limited to internal publicsector actors and is beginning to affect external governments, which are beginning to use and exchange data [42]. Big Data can include structured, unstructured or a combination of structured and unstructured data. Variability is the characteristic change in the format and structure of the source of Big Data. When processing raw data, unstructured data is converted into structured data. Data kind, for example, brings together scientists and statisticians with non-profit data work to overcome a lack of technology and human resources capable of handling Big Data projects [43]. This approach neglects the integrity of the public sector, its institutional norms and the value and uniqueness of public organisations in protecting the rule of law, political neutrality, democratic control, accountability, security and other noneconomic public values $[44,45]$. Close attention should be paid to the contemporary use of data analysis in government and public service settings with regard to how data analysis can be applied in the smart city environment.

\section{Conclusions and implications}

All in all, Big Data analytics has made many traditional methods of recording and analysing obsolete. The use of big data has enabled others to drive the delivery of data. Cities and companies produce much of their own data as a by-product of normal operations and invest heavily in the acquisition of relevant data from others. With the collection of databases and enormous data sets, the exchange of data between the parties has become simpler and more commonplace as a result of technological progress. The creation of smart cities depends on better organizations that can share and analyse the vast amount of data. Big Data plays a special role in the discussion of urban infrastructure, because it provides enormous amounts 
of information, much of it unstructured and at different levels. The analysis of Big Data offers the possibility of a comprehensive quantification of urban life, which is difficult to achieve through surveys and questionnaires alone. Our paper provided a definition of urban big data and examined its characteristics and applications in urban intelligence. It also highlighted the challenges in shaping and developing urban big data nowadays.

In summary, our results describe the networked nature of urban infrastructure and the benefits of Big Data. Data management can play a key role in the joint development of urban planning and infrastructure. This case study can support urban planning strategies for the development of a data-rich society. Big data is a huge amount of data that can be analysed by companies to make appropriate strategic steps and business decisions. Smart city managers can use bigdata analysis to monitor and anticipate urban phenomena in new ways by integrating sensors into urban infrastructure and by creating new sources of data, including citizens and their mobile devices. Citizens can connect data in a visible way and gain more insights through the ubiquitous presence of digital data technologies in cities. Moreover, there is huge potential to use big data to address many of the problems associated with smart cities by using analytics to find deeper insights and better decision-making practices. The cloud provides additional opportunities to implement and deploy ICT solutions for smart cities and support collaboration between various applications in cities. With huge advances in ICT, cloud and information technology, Big Data offers cities more opportunities to be as smart as possible in a short space of time. In this article, we propose IoT-based systems that harness the enormous amount of data generated by smart systems to build smart cities and urban planning for a bright future. This data is generated from smart home sensors, vehicle networks, weather and water sensors, intelligent parking systems, monitoring objects, etc.

Smart cities use information and communication technology to collect, process and implement data in a specific area. ICTs play an important role in smart cities by making the data collected by information technology components readily available. It works by communicating with connected devices and exchanging data without needing the Internet, wireless connection or any other communication medium. Sensors collect data from medical facilities to detect the spread of disease. Smart cities use information and communication technology to make changes to urban services by analysing data and feedback from citizens. Big Data affects various sectors of cities, including transport, public safety, urban budgets, and much more. Big Data from mobile devices and connected cars can help uncover gaps in public transport and expansion opportunities. By tracking trends, current usage, and projected growth, urban transport planners can predict where to expand capacity and add new routes. Track journeys on the last mile between transit stations, find places where driver-sharing or shuttle-only sharing is available, and planners can direct new transit investments to the most useful places. Optimize smart city services and operations by leveraging collected data and smart applications to improve services and identify infrastructure and environmental improvements that may be needed. Realisation of new development opportunities by observing current developments and their effects, as well as emerging problems and new requirements. Big Data infrastructure consists of various adoption processes such as cluster design, server architecture, network architecture, storage architecture, and information security architecture. An updated Big Data Infrastructure gives access, speed and availability of data to speed up making quick decisions and correcting actions. Big data solutions provide administrative control over large amounts of data, including storage, backup, analysis and visualization. Therefore, the primary role of big data cities is to facilitate information flow mechanisms for learning and coordination between heterogeneous individuals. Most companies use Network Attached Storage (NAS) and Storage Area Network (SAN) for Big Data implementation using existing infrastructure, but Direct Attached Storage (DAS) is also recommended. This outlines the basic concepts of smart cities and how Big Data will affect them. We show that Big Data is useful for urban planning, formalization of the planning 
process, and general arithmetic problems. Data is used to optimise urban operations, manage resources and improve the daily lives of citizens. Smart cities use technology to improve access to public transport, control traffic, optimize water and electricity supply, improve law enforcement, schools, hospitals and more. Many organisations worldwide rely on digital systems to achieve their goals. Also, the use of Big Data solutions in the financial services industry to analyse conversations on social networking websites has driven the growth of the Big Data infrastructure market. The growth of cloud-based Big Data analysis has accelerated the growth of Big Data-targeted software and programming. The growth of structured and unstructured data offers many opportunities for Big Data platforms. In short, urban development strategies for smart cities should focus on how to make citizens' lives healthier, easier to transport and communicate, and better serve humanity.

\section{References}

1. K. Kourtit, P. Nijkamp, J. Steenbruggen, Socio-Economic Planning Sciences, 58, 13-21 (2017)

2. C. Ratti, M. Claudel, The city of tomorrow: Sensors, networks, hackers, and the future of urban life (2016)

3. V. Chang, Technological Forecasting and Social Change, 165, 120559 (2021)

4. W. Strielkowski, T. Veinbender, M. Tvaronavičienè, N. Lace, Economic ResearchEkonomska Istraživanja, 33(1), 788-803 (2020)

5. T. Yigitcanlar, H. Han, M. Kamruzzaman, G. Ioppolo, J. Sabatini-Marques, Land Use Policy, 88, 104187 (2019)

6. S. Bibri, J. Krogstie, European Journal of Futures Research, 7(1), 1-20 (2019)

7. A. Osman, Future Generation Computer Systems, 91, 620-633 (2019)

8. W. Strielkowski, Social Impacts of Smart Grids: The Future of Smart Grids and Energy Market Design (2019)

9. M. Van Meeteren, A. Poorthuis, Urban Geography, 39(1), 122-148 (2018)

10. S. Bibri, Sustainable Cities and Society, 38, 230-253 (2018)

11. Y. Cao, H. Song, O. Kaiwartya, B. Zhou, Y. Zhuang, Y. Cao, X. Zhang, IEEE Communications Magazine, 56(3), 150-156 (2018)

12. S. Bibri, Computational Urban Science, 1(1), 1-32 (2021)

13. P. Čajka, Central European Political Studies, 4, 131-148 (2019)

14. Y. Wang, J. Taylor, M. Garvin, Journal of Management in Engineering, 36(4), 04020019 (2020)

15. N. Browne, Smart Cities, 3(2), 186-201 (2020)

16. C. Esposito, M. Ficco, B. Gupta, Information Processing \& Management, 58(2), 102468 (2021)

17. G. Rausser, W. Strielkowski, D. Štreimikienè, Energy \& Environment, 29(1), 131-146 (2018)

18. S. Bibri, J. Krogstie, Energy Informatics, 3(1), 1-59 (2020)

19. X. Zhang, X. Ming, D. Yin, Journal of Cleaner Production, 265, 121863 (2020)

20. O. Bayulgen, Energy Research \& Social Science, 62, 101376 (2020)

21. A. Seijas, M. Gelders, Urban Studies, 58(2), 316-334 (2021)

22. D. Horgan, B. Dimitrijević, Sustainable Cities and Society, 48, 101550 (2019) 
23. J. Kandt, M. Batty, Cities, 109, 102992 (2021)

24. M. Maksimovic, International Journal of Computing and Digital Systems, 6(04), 175184 (2017)

25. W. Strielkowski, E. Volkova, I. Pushkareva, D. Streimikiene, Energies, 12(7), 1392 (2019)

26. M. Khan, M. Babar, S. Ahmed, S. Shah, K. Han, Sustainable Cities and Society, 35, 271279 (2017)

27. S. Bibri, J. Krogstie, Sustainable Cities and Society, 32, 449-474 (2017)

28. H. Lim, A, Taeihagh, Energies, 11(5), 1062 (2018)

29. A. Ersoy, Regional Studies, Regional Science, 4(1), 26-31 (2017)

30. J. Niño-Amézquita, V. Dubrovsky A. Jankurová, Czech Journal of Social Sciences, Business and Economics, 6(1), 28-36 (2017)

31. H. Brady, Annual Review of Political Science, 22, 297-323 (2019)

32. World Bank, https://elibrary.worldbank.org/doi/abs/10.1596/27667 (2017)

33. J. Corburn, D. Vlahov, B. Mberu, L. Riley, W. Caiaffa, S. Rashid, H. Ayad, Journal of Urban Health, 97(3), 348-357 (2020)

34. A. Caragliu, C. Del Bo, Scienze Regionali, 17(1), 7-14 (2018)

35. R. Berney, Learning from Bogotá: pedagogical urbanism and the reshaping of public space (2017)

36. L. Tan, H. Arbabi, Q. Li, Y. Sheng, D. Tingley, M. Mayfield, D. Coca, Resources, Conservation and Recycling, 138, 172-182 (2018)

37. S. Cutter, L. Barnes, M. Berry, C. Burton, E. Evans, E. Tate, J. Webb, Global Environmental Change, 18(4), 598-606 (2008)

38. I. Agbehadji, B. Awuzie, A. Ngowi, R. Millham, International Journal of Environmental Research and Public Health, 17(15), 5330 (2020)

39. A. Erraissi, A. Belangour, International Journal of Engineering \& Technology, 7(4), 3607-3612 (2018)

40. I. Lindgren, C. Madsen, S. Hofmann, U. Melin, Government Information Quarterly, 36(3), 427-436 (2019)

41. M. Sumbal, E. Tsui, E. See-to, Journal of Knowledge Management, 21(1), 180-196 (2017)

42. C. Van Ooijen, B. Ubaldi, B. Welby, https://www.oecd-ilibrary.org/governance/a-datadriven-public-sector_09ab162c-en (2019)

43. D. Holmes, Big data: a very short introduction (2017)

44. K. Adnan, R. Akbar, K. Wang, International Journal of Recent Technology and Engineering (IJRTE), 8, 1398-1404 (2019)

45. L. Wang, Automatic Control and Information Sciences, 3(1), 8-15 (2017) 